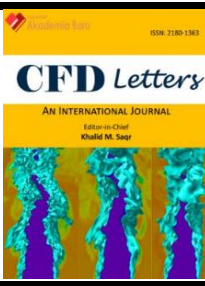

\title{
Heat and Fluid Flow Characteristics of Nanofluid in A Channel Baffled Opposite to The Heated Wall
}

\author{
Nguyen Minh Phu ${ }^{1,}{ }^{*}$, Pham Ba Thao ${ }^{1}$, Duong Cong Truyen ${ }^{1}$ \\ 1 Faculty of Heat and Refrigeration Engineering, Industrial University of Ho Chi Minh City (IUH), Vietnam
}

ARTICLE INFO ABSTRACT

\section{Article history:}

Received 22 November 2020

Received in revised form 16 January 2021

Accepted 23 January 2021

Available online 30 January 2021

\section{Keywords:}

Baffled channel; Cu-water nanofluid;

thermohydraulic performance; CFD

\begin{abstract}
In this paper, a nanofluid-based solar collector duct equipped with baffles is examined numerically. Baffles are located on the back plate to guide nanofluid flow toward absorber plate for heat transfer enhancement purposes. Cu-water nanofluid with fixed flow rate and concentration in the baffled duct are investigated for thermohydraulic mechanisms. Baffles with different inclination angles, heights and pitches are considered in this study. Numerical simulations are performed using Ansys fluent software with verified results compared to those of an experiment in the literature. The results show that the baffle angle $60^{\circ}$ causes the lowest thermohydraulic performance. Because in the angle range of 30 to $60^{\circ}$ the heat transfer is less variable while the pressure loss increases sharply. At the baffle pitch of $40 \mathrm{~mm}$, there is no reattachment point at the non-heated surface. At the angle of $90^{\circ}$, three eddies are formed around a baffle. The slope linear regression analysis yields that baffle height has the strongest effects on thermohydraulic performance followed by baffle pitch and baffle angle. Nanofluid pressure loss respectively increases with baffle height and baffle angle at the rate of 0.463675 and 0.0049607 while absorber plate temperature respectively decreases with the baffle height and baffle angle at the rate of -0.176746 and -0.001377 . Flow patterns and isotherms of all the cases examined are presented and analyzed in this study.
\end{abstract}

\section{Introduction}

Heat transfer enhancement is a topic of particular interest in the scientific and technical fields. This is due to the requirements for compact heat exchanger while ensuring heat capacity and the development of material science [1]. Solutions to improve heat transfer have be considered as follows. That may be the use of triple-fluid heat exchanger to reduce the heat transfer surface length $[2,3]$. Another measure employs a helically coiled tube due to the presence of two eddies in the spiral flow to increase heat transfer [4]. Recently, nano-fluid has been studied a lot because it has a higher thermal conductivity than water and the Brownian motion of nanoparticles which augments the heat transfer [5]. Meibodi et al., [6] have experimentally studied the flat plate collector to heat nanofluid

\footnotetext{
* Corresponding author.

E-mail address: nguyenminhphu@iuh.edu.vn (Nguyen Minh Phu)
} 
$\mathrm{SiO}_{2}$. The research has shown the appropriate flow rate and concentration of the nanofluid for the highest efficiency. Rashidi et al., [7] studied the nanofluid heater in which the solar absorber plate has wedge-shaped ribs. Design parameters including Reynolds number, wedge angle, relative roughness pitch, relative roughness height and nanofluid concentration were investigated in this study. Hawwash et al., [8] numerically investigated and experimented with nanofluid $\mathrm{Al}_{2} \mathrm{O}_{3}-\mathrm{H}_{2} \mathrm{O}$ in flat plate solar collector. They reported that the flow rate of $5.5 \mathrm{l} / \mathrm{min}$ reached maximum efficiency and pressure loss increased by $28 \mathrm{~Pa}$.

Heat transfer intensification using baffles have been figured out in the air channel studies [9]. Khan et al., [10] experimentally studied the fluid channel with perforated baffles and a roughened heating surface. The results showed that heat transfer increased by $326 \%$ and pressure loss increased by $250 \%$. Menasria et al., [11] numerically simulated an air collector duct with baffles attached on the back plate. They found that the Nusselt number increased by 3.72 times and the pressure loss increased by 14.47 times. Jedsadaratanachai and Boonloi [12] numerically studied the square channels with C-shaped plates. This pattern was shown the increase in eddy magnitude and perturbation of the thermal boundary layer leading to increase heat transfer effectiveness. Dutta and Hossain [13] experimentally studied the baffles sloped in the direction of flow. There were holes with diameter of $1.07 \mathrm{~cm}$ on the baffle. They reported that Nusselt number increased 5 times compared with smooth duct. Dutta and Dutta [14] tested 8 different types of baffle in a rectangular channel with single baffle. They recommend that the baffle should be placed in the high heat flux area to increase heat transfer effectiveness. Ary et al., [15] experimented and simulated to compare 1-plate and 2-plate channels. The difference is between the plate and the heat exchange surface having a gap of $0.4 \mathrm{~cm}$ to avoid dead eddies. They concluded that the 2-plate type gave better heat transfer efficiency. Chamoli and Thakur [16] simulated the perforated plates perpendicular to the duct wall. The results showed that heat transfer increased 3.1 times and pressure loss increased 2.2 times. Karami et al., [17] used a V-ribbed absorber plate to investigate heat transfer with graphene oxide nanofluid. They found a $26.7 \%$ increase in heat transfer coefficient over the traditional type. A combination of nanofluid and a roughened heat transfer surface is often used to diminish viscous sub-layer near the surface. The different roughness shapes in the nano-fluid channel such as trapezoid, groove, and triangle can be found in open publications $[18,19]$. Baffled channels with various configurations and arrangements contributed for heat transfer augmentation such as perforated baffles, corrugated Baffles, two inclined baffles, corrugated walls [20-24]. Complicated insertions in microchannel for heat transfer enhancement were figured out in the literature $[25,26]$.

From the above survey it can be seen that the baffled duct of nanofluid-based solar collector studies is not investigated. Although the baffles were proven to have advantages in air channels $[27,28]$. It is the flow acceleration adjacent the absorber surface and the impingement heat transfer. In this study, different configurations of baffle which mounted opposite to the absorber surface were investigated to assess variation in heat transfer and pressure loss across the duct.

\section{Model Description}

Figure 1 shows a nanofluid-based solar collector duct with a baffled bottom plate. In this study, the length of collector duct is $500 \mathrm{~mm}$, height $\mathrm{H}=20 \mathrm{~mm}$, width $\mathrm{W}=300 \mathrm{~mm}$. Upstream and downstream of the test section are attached ducts with length of $250 \mathrm{~mm}$ and $150 \mathrm{~mm}$, respectively. The entrance duct allows the fully developed flow prior to heat exchange surface. Whereas, the exit duct is to eliminate the strong swirl behind the baffle and mix the streams. Key geometry parameters include baffle angle a, baffle height e, and baffle pitch P. In this study, each key is performed in 3 levels as follows: $\mathrm{a}=30,60,90^{\circ}, \mathrm{e}=10,12.5,15 \mathrm{~mm}, \mathrm{P}=40,80,120 \mathrm{~mm}$. The boundary conditions 
included the nanofluid velocity and temperature at the inlet: $V=4.2 \mathrm{~mm} / \mathrm{s}$ and $T_{\text {inlet }}=300 \mathrm{~K}$, the uniform heat flux of $1000 \mathrm{~W} / \mathrm{m}^{2}$ at the absorber plate and the atmospheric pressure at the outlet. Eq. (1)-(4) present the calculated thermophysical parameters for Cu-water nanofluid [29]. The nanofluid concentration of $\phi=1 \%$ has been fixed. The thermophysical properties of $\mathrm{Cu}$ and water used to estimate properties of $\mathrm{Cu}$-water nanofluid are presented in Table 1.

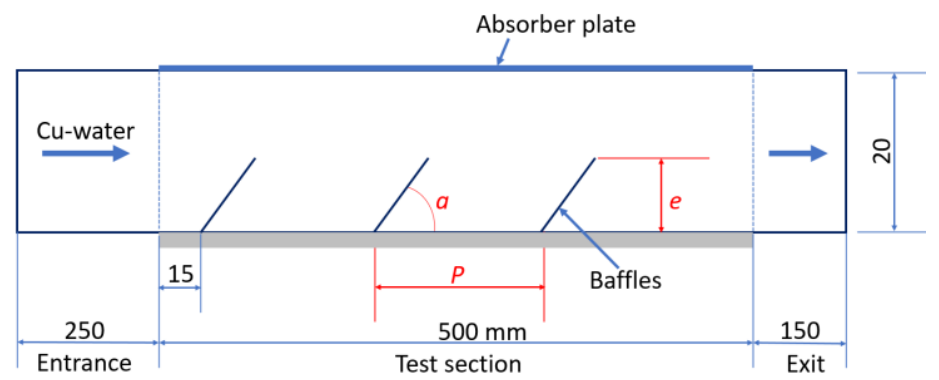

Fig. 1. Physical domain

$\rho_{n f}=(1-\phi) \rho_{w}+\phi \rho_{s}$

$c_{p, n f}=\frac{\phi \rho_{s} c_{p_{s}}+(1-\phi) \rho c_{p, w}}{\rho_{n f}}$

$k_{n f}=k_{w} \frac{k_{s}+2 k_{w}+2 \phi\left(k_{s}-k_{w}\right)}{k_{s}+2 k_{w}-\phi\left(k_{s}-k_{w}\right)}$

$\mu_{n f}=\frac{\mu_{w}}{(1-\phi)^{2.5}}$

where $\rho, c_{p}, k, \mu, \phi$ are respectively density, specific heat, thermal conductivity, dynamic viscosity, volume fraction of nanoparticles. Subscripts $\mathrm{nf}, \mathrm{w}$ and $\mathrm{s}$ denote nanofluid, base fluid (water) and solid particles.

Table 1

Thermophysical properties of water and Cu particle

\begin{tabular}{lll}
\hline Properties & Water & Cu particle \\
\hline Density $\left(\mathrm{kg} \mathrm{m}^{-3}\right)$ & 996.5 & 8300 \\
Specific heat $\left(\mathrm{J} \mathrm{kg}^{-1} \mathrm{~K}^{-1}\right)$ & 4183 & 420 \\
Thermal conductivity $\left(\mathrm{W} \mathrm{m}^{-1} \mathrm{~K}^{-1}\right)$ & 0.5981 & 401 \\
Viscosity $\left(\mathrm{kg} \mathrm{m}^{-1} \mathrm{~s}^{-1}\right)$ & 0.0008514 & \\
\hline
\end{tabular}

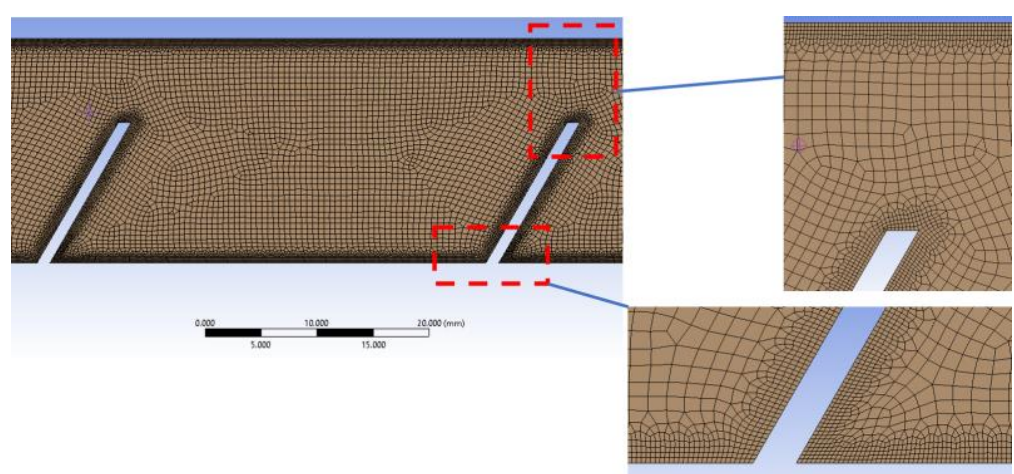

Fig. 2. Meshing with refinement at walls in test section 
Figure 2 shows the meshing of the computational domain in this study. The walls in the test section are refined to increase accuracy for near wall treatment. In addition, further refinement by adapting the $\mathrm{y}^{+}$(nondimensional wall distance) value is lower than unity for the enhanced wall treatment $[30,31]$. Table 2 shows the mesh quality criteria implemented for a typical case. It can be seen that all criteria are satisfactory. 2D numerical simulation using the standard $k-\varepsilon$ turbulence model was performed in Ansys fluent 16 software [32]. Residuals of $1 \mathrm{e}-6$ is set for all governing equations. Ansys-based calculations were conducted on a computer equipped with Intel Core i7 Processor, $2.60 \mathrm{GHz}$ of clock speed and $8.0 \mathrm{~GB}$ of RAM. The convergence was reached after about 4500 iterations and maximum computational time of three hours. Grid independent testing was carried out with the number of elements between 70000 and 180000 . Figure 3 shows that the numerical output does not change significantly with the number of elements from 120000 . Hence these settings are applicable to all cases studied. Convection heat transfer coefficient $(\mathrm{h})$ in Figure 3 is deduced from the simulation results including outlet nanofluid temperature $T_{\text {outlet, }}$ absorber plate temperature $T_{a p}$ :

$h=\frac{\dot{m} c_{p, n f}\left(T_{\text {outlet }}-T_{\text {inlet }}\right)}{A_{a p}\left(T_{a p}-T_{f}\right)}$

where $\dot{m}, \mathrm{~A}_{\mathrm{ap}}, \mathrm{T}_{\mathrm{f}}$ are respectively nanofluid mass flow rate, absorber plate area, mean nanofluid temperature. $T_{f}=0.5\left(T_{\text {inlet }}+T_{\text {outlet }}\right)$. -

Table 2

Mesh quality

\begin{tabular}{|c|c|c|}
\hline Criterion & Present simulation & Desirable \\
\hline Aspect ratio & Max. 2.9839 & Maximum < 35:1 [32] \\
\hline \multirow[t]{2}{*}{ Skewness } & Max. 0.80465 & Maximum < 0.95 \\
\hline & Average 0.090393 & Average $<0.33[32]$ \\
\hline Orthogonal quality & Average 0.9829 & $\begin{array}{l}\text { Range from } 0 \text { to } 1 \text {, values close to } 0 \\
\text { correspond to low quality [32] }\end{array}$ \\
\hline Dimensionless wall distance $\left(\mathrm{y}^{+}\right)$ & Average 0.1632322 & $<1[33-35]$ \\
\hline
\end{tabular}

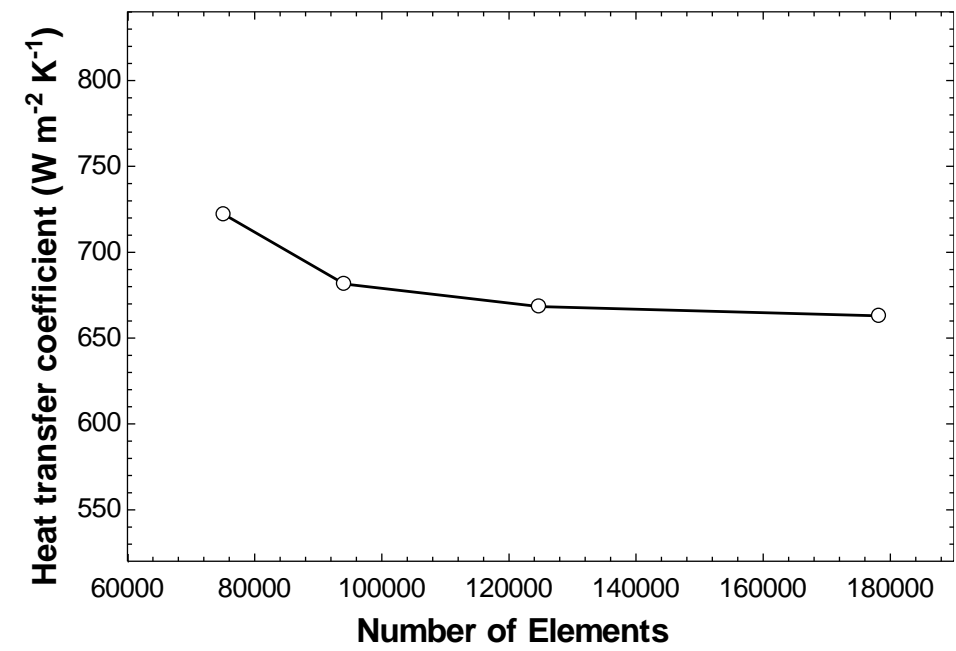

Fig. 3. Grid independence test

Figure 4 shows the comparison of current simulation results with experimental data [36]. In the experimental study, an inclined baffle is placed opposite the heating plate in order to examine the heat and air fluid flow. The experimental channel dimensions (millimeters) can be seen in Figure 4(a) 
with a channel width of $140 \mathrm{~mm}$. There is a good match between results obtained from the numerical methodology above and the experimental results. These numerical settings are therefore used to investigate the effect of the geometrical parameters of the inclined baffle on the thermohydraulic behavior. In Figure 4(b), $\Delta \mathrm{P}$ is the differential pressure across the test section. Nusselt number and Reynolds number are defined as Eq. (6) and Eq. (7):

$N u=\frac{h D_{h}}{k}$

$R e=\frac{\rho V D_{h}}{\mu}$

where $\mathrm{D}_{\mathrm{h}}$ is hydraulic diameter, $D_{h}=\frac{4 W H}{2(W+H)}$.
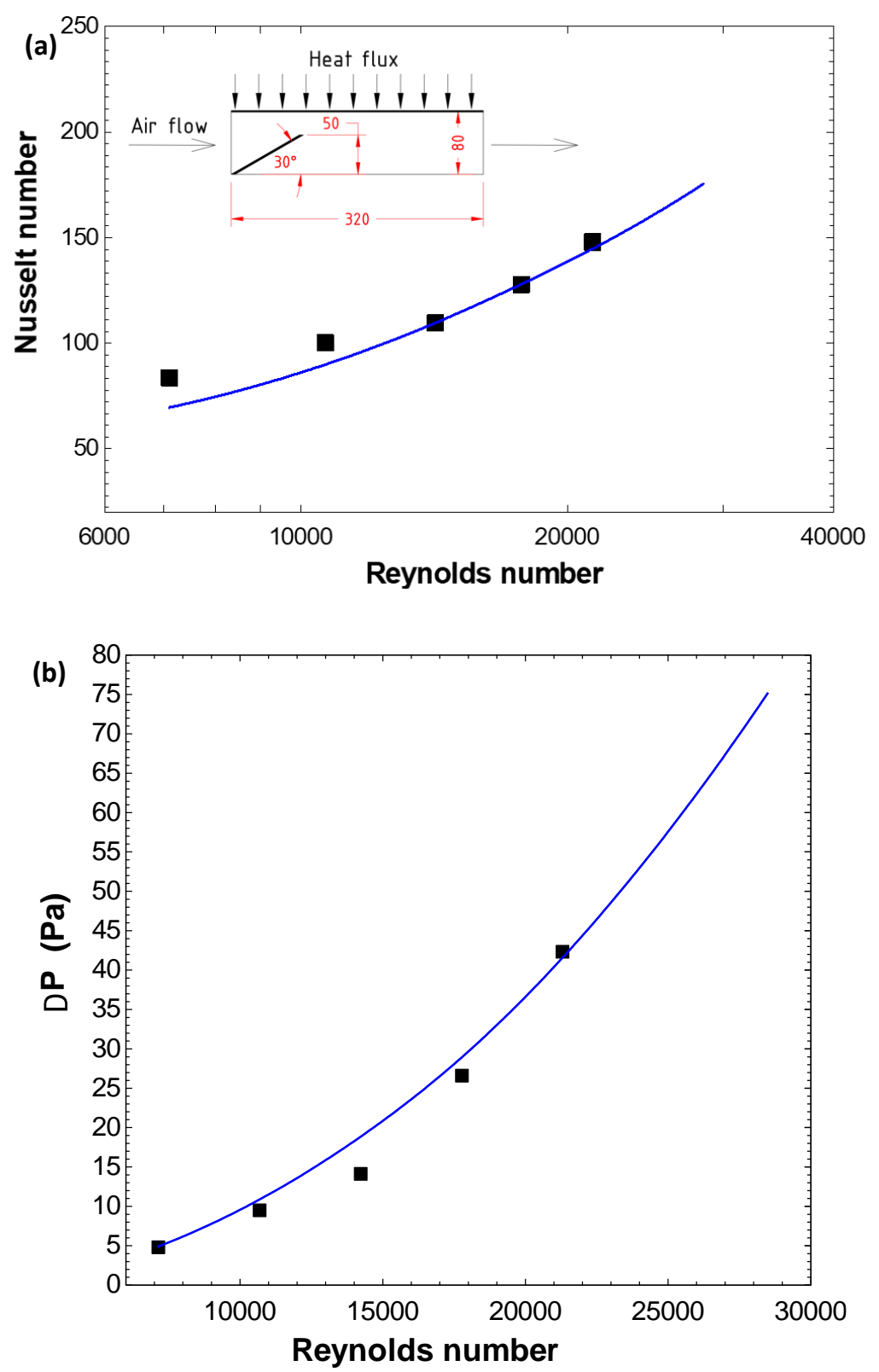

Fig. 4. Validation of the present study (curves) with experimental results (symbols); (a) Nusselt number as a function of Reynolds number, (b) Pressure loss as a function of Reynolds number [36] 


\section{Results and Discussion}

\subsection{Effects of Baffle Pitch}

Figure 5 and Figure 6 show the change in temperature and streamlines of nanofluid with different baffle pitches at the baffle height and baffle angle of $12.5 \mathrm{~mm}$ and $60^{\circ}$, respectively. It can be seen in Figure 5 that the absorber surface temperature and the nanofluid temperature difference in the duct increase with the baffle pitch. In other words when increasing the baffle pitch, the heat transfer efficiency decreases. This is because when the baffle pitch is small, the nanofluids approach the absorber surface at high velocity, intensifying heat transfer. This can be seen clearly through the streamlines in Figure 6 . At $P=40 \mathrm{~mm}$, only presence of the vortex in the region between the two successive baffles which increases heat transfer but also obviously redoubles the pressure loss penalty [37]. When increasing the baffle pitch to $P=80 \mathrm{~mm}$, reattachment point and laminar sublayer appear on the non-heated surface. As the pitch increases, the length of the layer becomes longer. From the velocity profile it can be seen that the region just downstream of the baffle has the intensified heat transfer due to the double effect of the high velocity and impingement on the absorber surface. These phenomena augment heat transfer to the nanofluid flow in the channel that has baffles mounted opposite the heat exchange surface. Adopting the slope linear regression through numeric data deduced from the simulation as seen in Figure 7, it is worth remarking that pressure loss $(\Delta \mathrm{P})$ decreases with increase in baffle pitch at the rate of -0.0117303 while absorber plate temperature $\left(T_{a p}\right)$ increases with the pitch at the rate of 0.00787513 [34]. It should be noted that increase in absorber plate temperature with the pitch implies a reduced heat transfer mechanism.

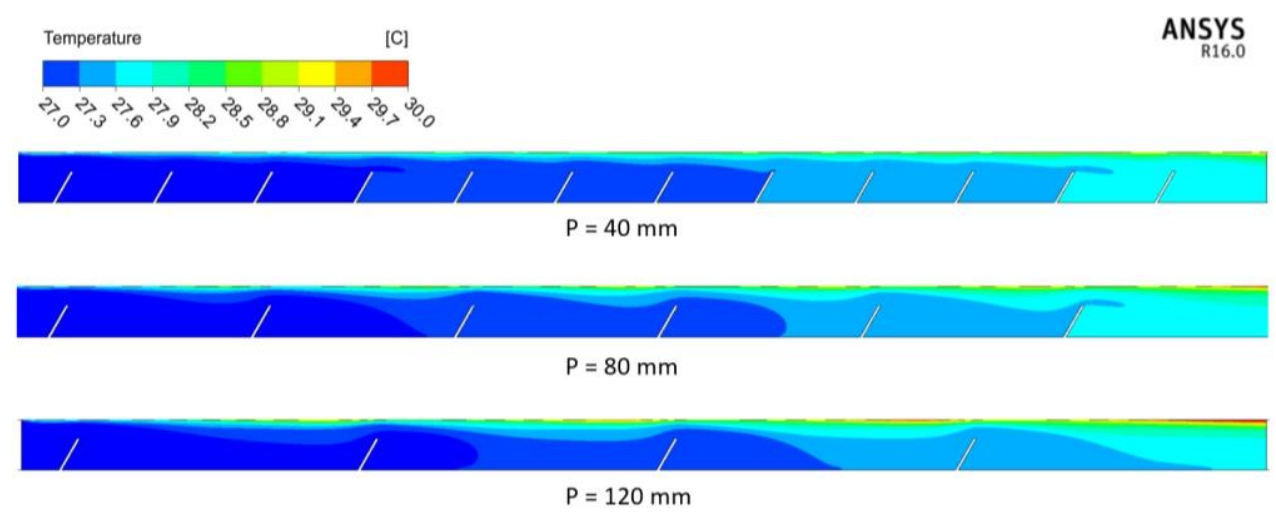

Fig. 5. Isotherms with baffle pitches at fixed values of $\mathrm{e}=12.5 \mathrm{~mm}$ and $\mathrm{a}=60^{\circ}$
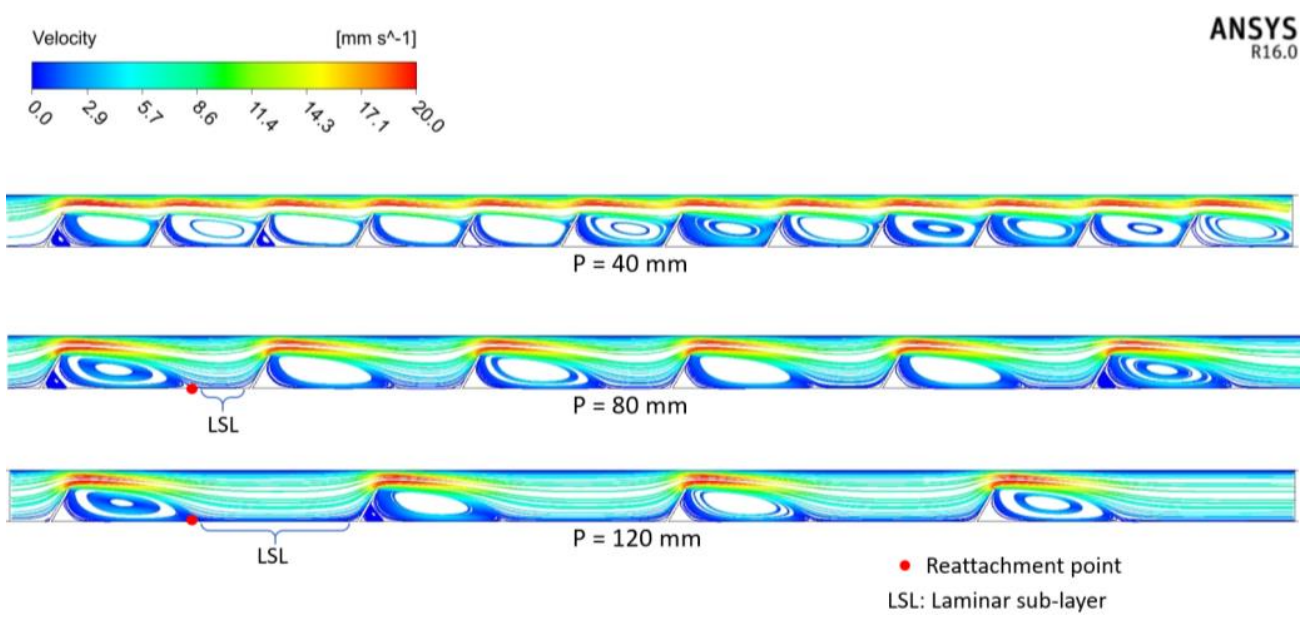

Fig. 6. Streamlines with baffle pitches at fixed values of $\mathrm{e}=12.5 \mathrm{~mm}$ and $\mathrm{a}=60^{\circ}$ 


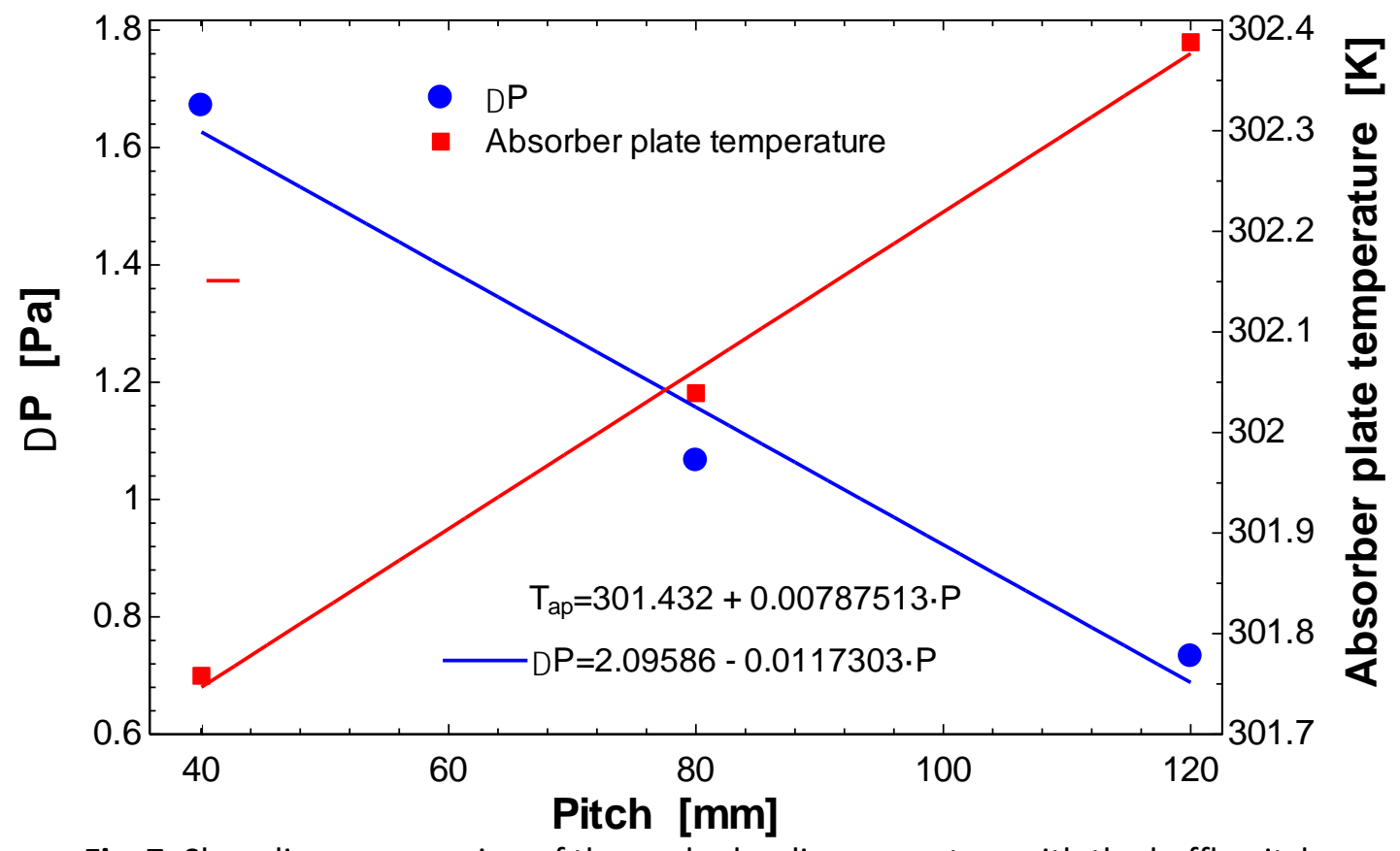

Fig. 7. Slope linear regression of thermohydraulic parameters with the baffle pitch

\subsection{Effects of Baffle Height}

Temperature contour and streamlines varied with baffle height can be seen in Figure 8 and Figure 9 with baffle pitch of $80 \mathrm{~mm}$ and angle baffle of $60^{\circ}$. It is clearly seen that when the baffle height increases, the absorber plate temperature decreases. In addition, at a large baffle pitch, the nanofluid temperature rises more rapidly along the length of the solar collector duct. The nanofluid in the middle of the $4^{\text {th }}$ and $5^{\text {th }}$ baffles reached a temperature of about $27.5^{\circ} \mathrm{C}$ at $\mathrm{e}=15 \mathrm{~mm}$. But for the same position, the nanofluid at the case e $=10 \mathrm{~mm}$ is still close to the inlet temperature, i.e., $27^{\circ} \mathrm{C}$. As the baffle height increases, the fluid is accelerated and a secondary vortex is markedly formed at the maximum baffle height as shown in Figure 9. These features develop both heat transfer and pressure loss with increasing of baffle height. Figure 10 demonstrates that pressure loss rises sharply with baffle height at the rate of 0.463675 and absorber plate temperature diminishes with the height at the rate of -0.176746 .

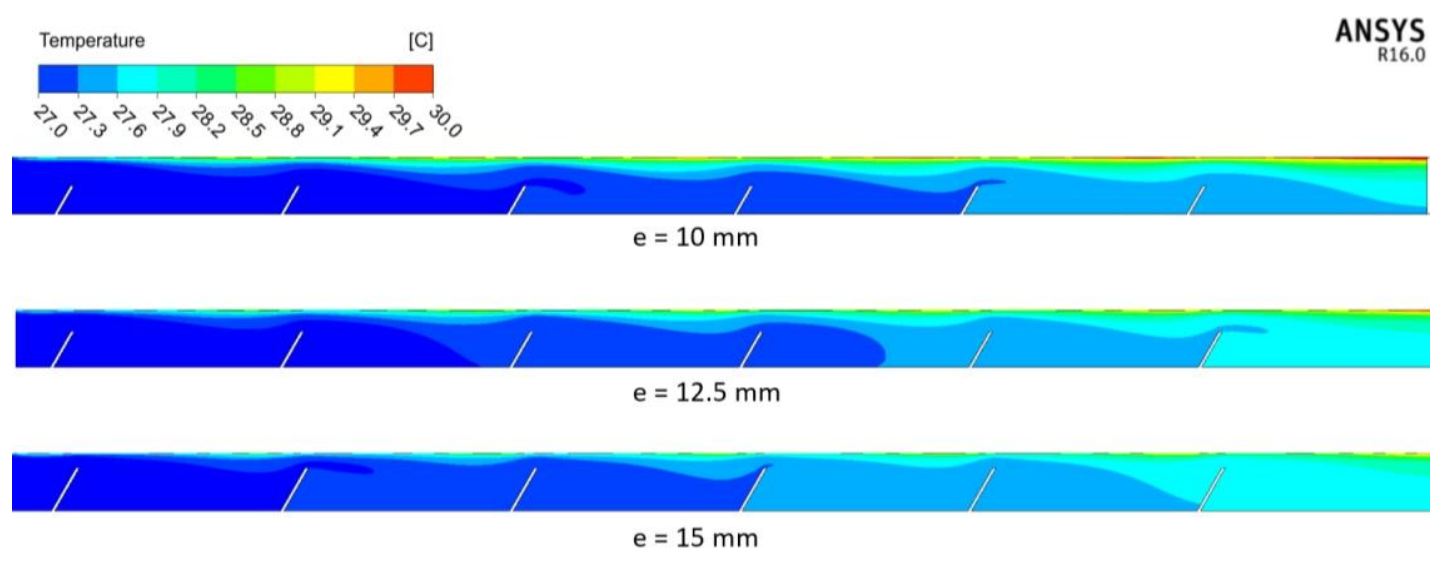

Fig. 8. Isotherms with baffle heights at fixed values of $P=80 \mathrm{~mm}$ and $\mathrm{a}=60^{\circ}$ 

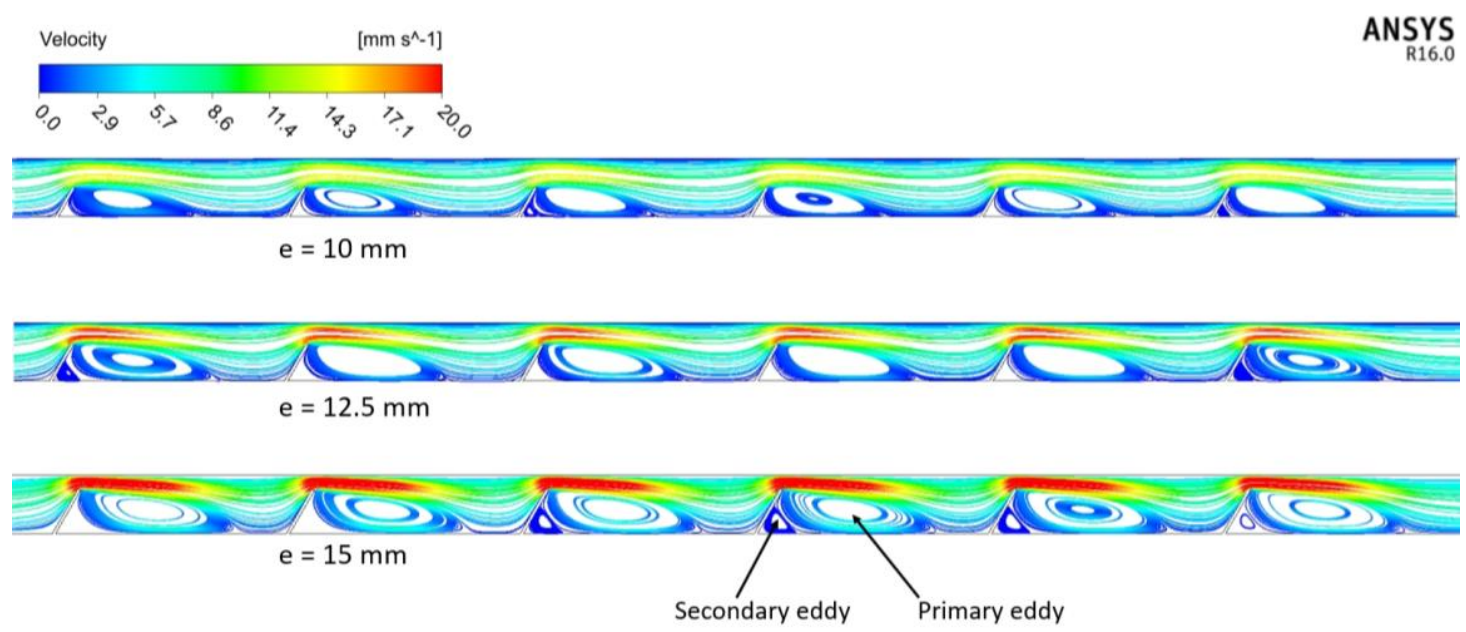

Fig. 9. Streamlines with baffle heights at fixed values of $P=80 \mathrm{~mm}$ and $\mathrm{a}=60^{\circ}$

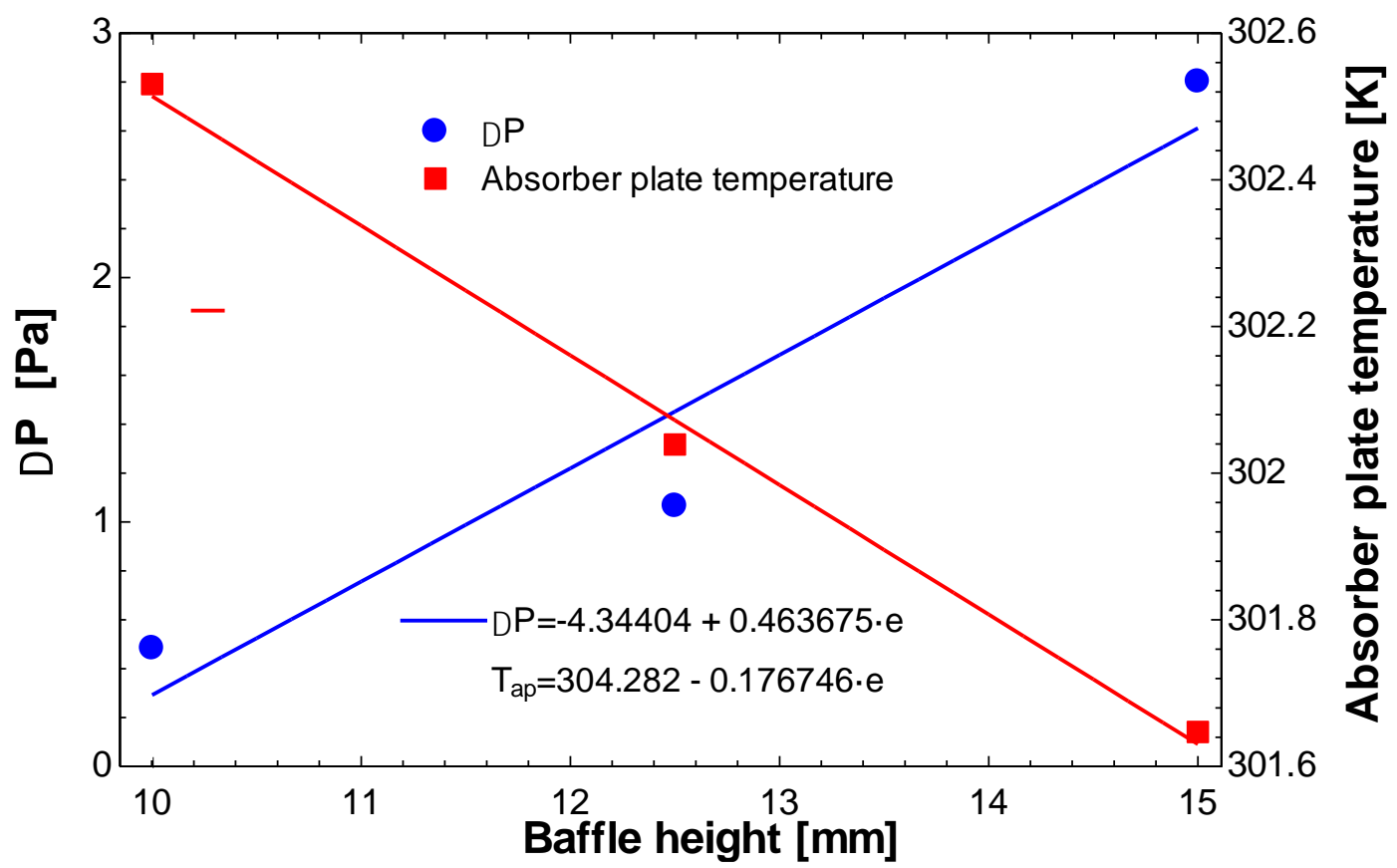

Fig. 10. Slope linear regression of thermohydraulic parameters with the baffle height

\subsection{Effects of Baffle Angle}

The variation of the temperature and the flow pattern with the baffle angle is shown in Figure 11 and Figure 12. It can be seen in Figure 11 that the inclination angle has little effect on the nanofluid temperature variation. A better temperature rise with an increase in the baffle angle can be observed. The third vortex forms markedly in the case of the baffle perpendicular to the flow $(a=$ $90^{\circ}$ ) as shown in Figure 12. The third vortex, together with the primary and secondary eddies, enhances the nanofluid disturbance in the duct resulting in enhancement in both heat transfer rate and pressure loss penalty. In addition, the vertical velocity component increases the heat transfer due to impingement effect. Figure 13 reveals that pressure loss rises slightly with baffle angle at the rate of 0.00496068 and absorber plate temperature decreases negligibly with the angle at the rate of -0.00137667 . 


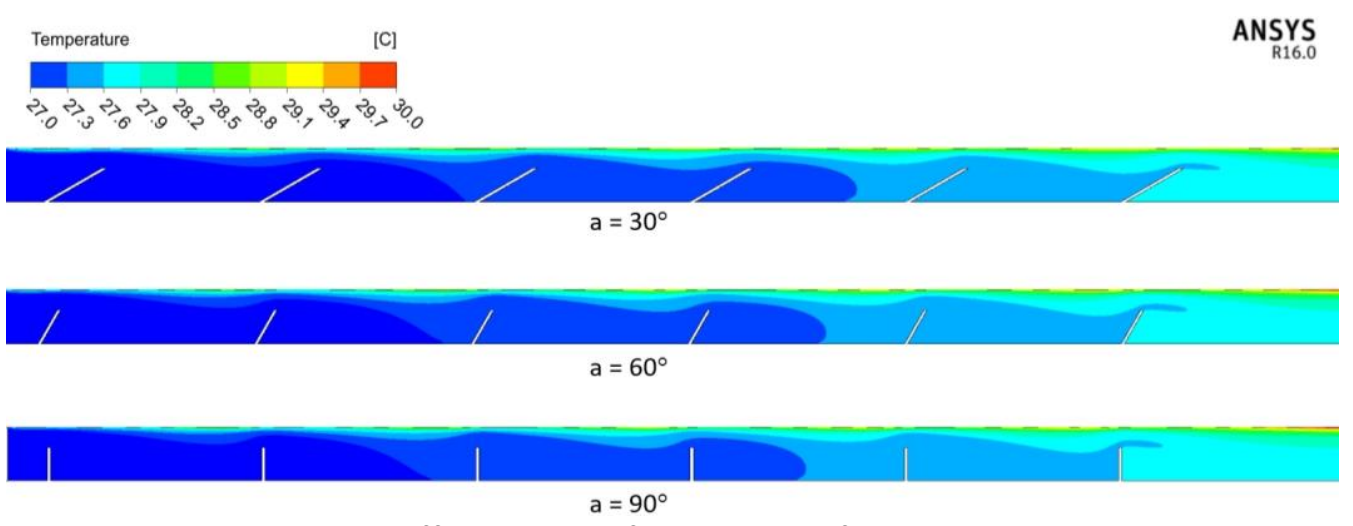

Fig. 11. Isotherms with baffle angles at fixed values of $P=80 \mathrm{~mm}$ and $\mathrm{e}=12.5 \mathrm{~mm}$
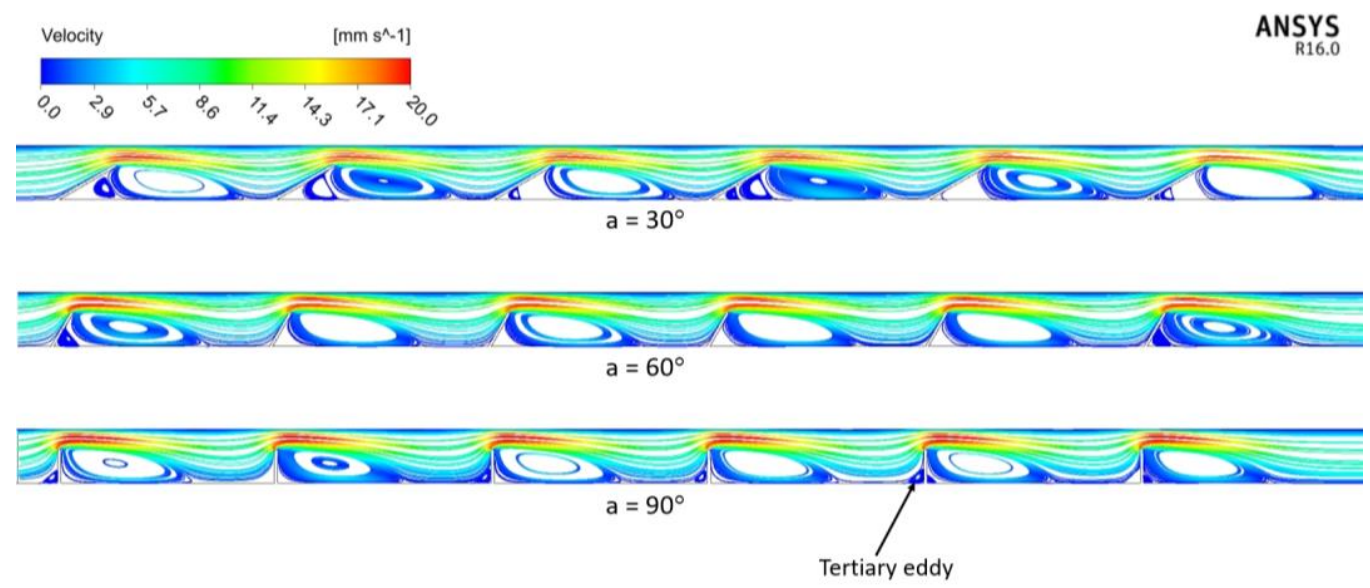

Fig. 12. Streamlines with baffle angles at fixed values of $P=80 \mathrm{~mm}$ and $e=12.5 \mathrm{~mm}$

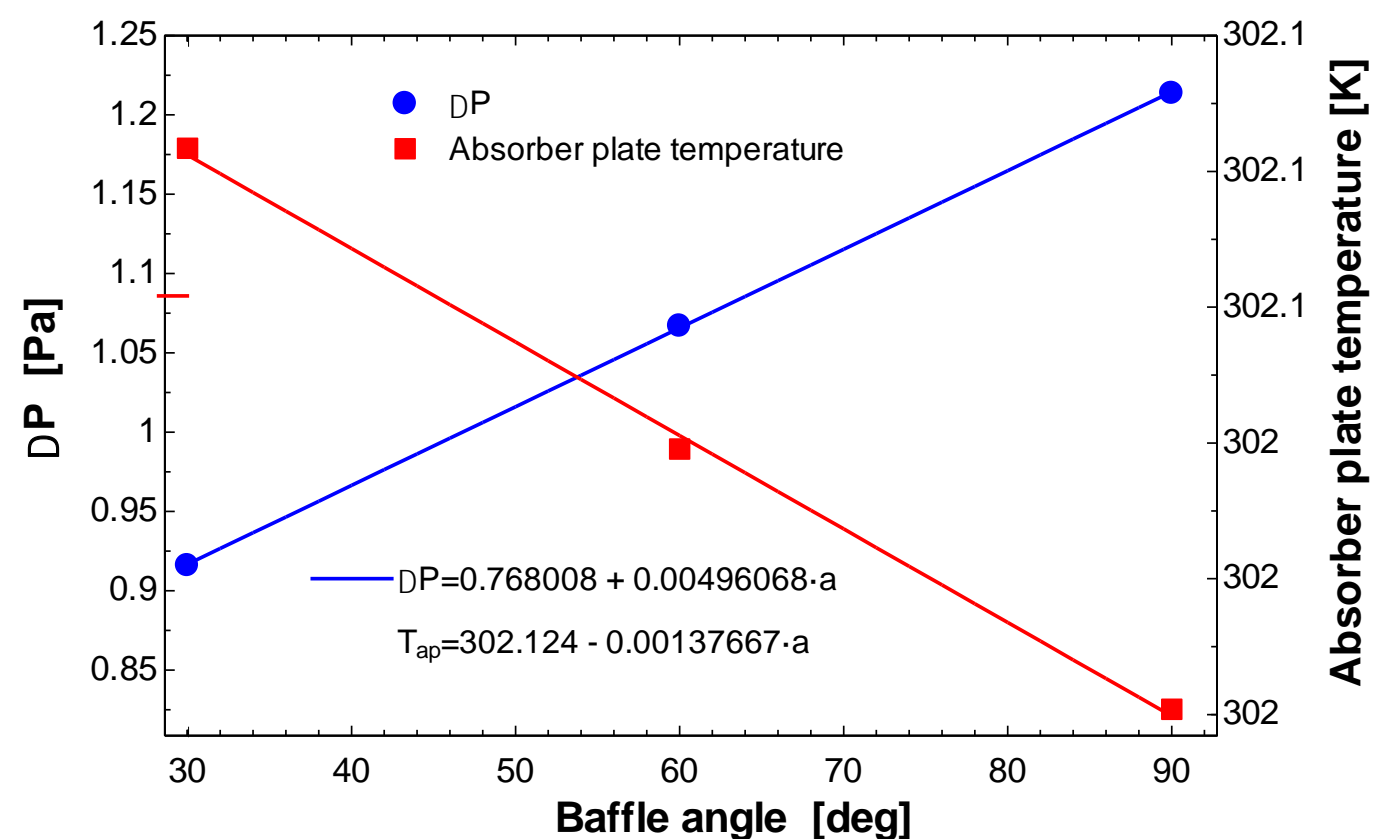

Fig. 13. Slope linear regression of thermohydraulic parameters with the baffle angle

\section{Conclusions}

The thermohydraulic characteristics of $\mathrm{Cu}$-water nanofluid in solar collector are presented in this study. The nanofluid flow rate and concentration were fixed to study the effects of geometry 
parameters of the baffle that were mounted opposite the absorber plate. This configuration accelerates the flow and forms impingement flow at the plate resulting in enhanced heat transfer. 2D numerical simulations were performed in the study with experimental confirmation. Some conclusions are drawn from this study:

I. At the baffle pitch of $40 \mathrm{~mm}$, reattachment point does not form on back plate of the collector.

II. The baffle height has a strong influence on the heat transfer and flow characteristics in the channel. When the height reaches $15 \mathrm{~mm}$, the secondary vortex forms strongly.

III. When the baffle angle is at $90^{\circ}$, a third vortex formed at the upstream of the baffle and impingement heat transfer is the strongest.

\section{References}

[1] Nguyen, Minh Phu, Tu Thien Ngo, and Thanh Danh Le. "Experimental and numerical investigation of transport phenomena and kinetics for convective shrimp drying." Case Studies in Thermal Engineering 14 (2019): 100465. https://doi.org/10.1016/i.csite.2019.100465

[2] Tuyen, Vo, Nguyen Van Hap, and Nguyen Minh Phu. "Thermal-hydraulic characteristics and optimization of a liquidto-suction triple-tube heat exchanger." Case Studies in Thermal Engineering (2020): 100635. https://doi.org/10.1016/i.csite.2020.100635

[3] Minh, Phu Nguyen. "A Compact EES Program to Predict Axial Temperature Distribution in Triple-fluid Heat Exchanger." Science \& Technology Development Journal-Engineering and Technology 3, no. 3 (2020): 452-460. https://doi.org/10.32508/stdjet.v3i3.736

[4] Phu, Nguyen Minh, and Nguyen Thi Minh Trinh. "Modelling and experimental validation for off-design performance of the helical heat exchanger with LMTD correction taken into account." Journal of Mechanical Science and Technology 30, no. 7 (2016): 3357-3364. https://doi.org/10.1007/s12206-016-0645-0

[5] Xiong, Qingang, Mehdi Vahabzadeh Bozorg, Mohammad Hossein Doranehgard, Kun Hong, and Giulio Lorenzini. "A CFD investigation of the effect of non-Newtonian behavior of $\mathrm{Cu}$-water nanofluids on their heat transfer and flow friction characteristics." Journal of Thermal Analysis and Calorimetry 139, no. 4 (2020): 2601-2621. https://doi.org/10.1007/s10973-019-08757-w

[6] Meibodi, Saleh Salavati, Ali Kianifar, Omid Mahian, and Somchai Wongwises. "Second law analysis of a nanofluidbased solar collector using experimental data." Journal of Thermal Analysis and Calorimetry 126, no. 2 (2016): 617625. https://doi.org/10.1007/s10973-016-5522-7

[7] Rashidi, Saman, Parniyan Javadi, and Javad Abolfazli Esfahani. "Second law of thermodynamics analysis for nanofluid turbulent flow inside a solar heater with the ribbed absorber plate." Journal of Thermal Analysis and Calorimetry 135, no. 1 (2019): 551-563.

https://doi.org/10.1007/s10973-018-7164-4

[8] Hawwash, A. A., Ali K. Abdel Rahman, S. A. Nada, and S. Ookawara. "Numerical investigation and experimental verification of performance enhancement of flat plate solar collector using nanofluids." Applied Thermal Engineering 130 (2018): 363-374. https://doi.org/10.1016/i.applthermaleng.2017.11.027

[9] Phu, Nguyen Minh. "Overall optimization and exergy analysis of an air conditioning system using a series-series counterflow arrangement of water chillers." International Journal of Air-Conditioning and Refrigeration 27, no. 04 (2019): 1950034.

https://doi.org/10.1142/S2010132519500342

[10] Khan, Jamil A., Jason Hinton, and Sarah C. Baxter. "Enhancement of heat transfer with inclined baffles and ribs combined." Journal of Enhanced Heat Transfer 9, no. 3\&4 (2002).

http://dx.doi.org/10.1080/10655130215738

[11] Menasria, Fouad, Merouane Zedairia, and Abdelhafid Moummi. "Numerical study of thermohydraulic performance of solar air heater duct equipped with novel continuous rectangular baffles with high aspect ratio." Energy 133 (2017): 593-608.

http://dx.doi.org/10.1016/j.energy.2017.05.002

[12] Jedsadaratanachai, Withada, and Amnart Boonloi. "Flow and Heat Transfer Characteristics of Air in Square Channel Heat Exchanger With C-Shaped Baffle: A Numerical Study." Frontiers in Heat and Mass Transfer (FHMT) 13 (2019). https://doi.org/10.5098/hmt.13.23 
[13] Dutta, Prashanta, and Akram Hossain. "Internal cooling augmentation in rectangular channel using two inclined baffles." International Journal of Heat and Fluid Flow 26, no. 2 (2005): 223-232. https://doi.org/10.1016/i.ijheatfluidflow.2004.08.001

[14] Dutta, Prashanta, and Sandip Dutta. "Effect of baffle size, perforation, and orientation on internal heat transfer enhancement." International Journal of Heat and Mass Transfer 41, no. 19 (1998): 3005-3013. https://doi.org/10.1016/S0017-9310(98)00016-7

[15] Ary, B. K. P., M. S. Lee, S. W. Ahn, and D. H. Lee. "The effect of the inclined perforated baffle on heat transfer and flow patterns in the channel." International Communications in Heat and Mass Transfer 39, no. 10 (2012): 15781583.

http://dx.doi.org/10.1016/i.icheatmasstransfer.2012.10.010

[16] Chamoli, Sunil, and Narendra Singh Thakur. "Numerical based heat transfer and friction factor correlations of rectangular ducts roughened with transverse perforated baffles." Walailak Journal of Science and Technology (WJST) 11, no. 2 (2014): 107-127. https://doi.org/10.2004/wjst.v11i2.594

[17] Karami, Maryam, Shahram Delfani, and Mostafa Esmaeili. "Effect of V-shaped rib roughness on the performance of nanofluid-based direct absorption solar collectors." Journal of Thermal Analysis and Calorimetry 138, no. 1 (2019): 559-572. https://doi.org/10.1007/s10973-019-08129-4

[18] Andreozzi, Assunta, Oronzio Manca, Sergio Nardini, and Daniele Ricci. "Forced convection enhancement in channels with transversal ribs and nanofluids." Applied Thermal Engineering 98 (2016): 1044-1053. https://doi.org/10.1016/i.applthermaleng.2015.12.140.

[19] Al-Shamani, Ali Najah, K. Sopian, H. A. Mohammed, Sohif Mat, Mohd Hafidz Ruslan, and Azher M. Abed. "Enhancement heat transfer characteristics in the channel with Trapezoidal rib-groove using nanofluids." Case Studies in Thermal Engineering 5 (2015): 48-58. https://doi.org/10.1016/i.csite.2014.12.003.

[20] Menni, Younes, and Houari Ameur. "Improvement of the performance of solar channels by using vortex generators and hydrogen fluid." Journal of Thermal Analysis and Calorimetry (2020): 1-22. https://doi.org/10.1007/s10973-020-10239-3

[21] Ameur, Houari, and Younes Menni. "Laminar cooling of shear thinning fluids in horizontal and baffled tubes: Effect of perforation in baffles." Thermal Science and Engineering Progress 14 (2019): 100430.

https://doi.org/10.1016/j.tsep.2019.100430

[22] Ameur, Houari. "Effect of corrugated baffles on the flow and thermal fields in a channel heat exchanger." Journal of Applied and Computational Mechanics 6, no. 2 (2020): 209-218. https://doi.org/10.22055/jacm.2019.28936.1521

[23] Ameur, Houari. "Effect of the baffle inclination on the flow and thermal fields in channel heat exchangers." Results in Engineering 3 (2019): 100021.

https://doi.org/10.1016/j.rineng.2019.100021

[24] Ameur, Houari, and Djamel Sahel. "Effect of some parameters on the thermohydraulic characteristics of a channel heat exchanger with corrugated walls." Journal of Mechanical and Energy Engineering 3 (2019). https://doi.org/10.30464/imee.2019.3.1.53

[25] Japar, Wan Mohd Arif Aziz, Nor Azwadi Che Sidik, and Shabudin Mat. "A comprehensive study on heat transfer enhancement in microchannel heat sink with secondary channel." International Communications in Heat and Mass Transfer 99 (2018): 62-81. https://doi.org/10.1016/i.icheatmasstransfer.2018.10.005

[26] Japar, Wan Mohd Arif Aziz, Nor Azwadi Che Sidik, Rahman Saidur, Yutaka Asako, and Siti Nurul Akmal Yusof. "A review of passive methods in microchannel heat sink application through advanced geometric structure and nanofluids: Current advancements and challenges." Nanotechnology Reviews 9, no. 1 (2020): 1192-1216. https://doi.org/10.1515/ntrev-2020-0094

[27] Luan, Nguyen Thanh, and Nguyen Minh Phu. "Thermohydraulic correlations and exergy analysis of a solar air heater duct with inclined baffles." Case Studies in Thermal Engineering (2020): 100672. https://doi.org/10.1016/i.csite.2020.100672

[28] Phu, Nguyen Minh, and Nguyen Thanh Luan. "A Review of Energy and Exergy Analyses of a Roughened Solar Air Heater." Journal of Advanced Research in Fluid Mechanics and Thermal Sciences 77, no. 2 (2020): 160-175. https://doi.org/10.37934/arfmts.77.2.160175

[29] Nakhchi, M. E., and J. A. Esfahani. "Numerical investigation of turbulent Cu-water nanofluid in heat exchanger tube equipped with perforated conical rings." Advanced Powder Technology 30, no. 7 (2019): 1338-1347. https://doi.org/10.1016/i.apt.2019.04.009 
[30] Mai, Thanh Dam, and Jaiyoung Ryu. "Effects of Leading-Edge Modification in Damaged Rotor Blades on Aerodynamic Characteristics of High-Pressure Gas Turbine." Mathematics 8, no. 12 (2020): 2191.

https://doi.org/10.3390/math8122191

[31] Phu, Nguyen Minh, and Nguyen Van Hap. "Numerical Investigation of Natural Convection and Entropy Generation of Water near Density Inversion in a Cavity Having Circular and Elliptical Body." In Fluid-Structure Interaction. IntechOpen, 2020.

https://doi.org/10.5772/intechopen.95301

[32] ANSYS. Ansys Fluent Theory Guide 16.0. ANSYS, Inc. (2015).

[33] Karimi, Yavar, Ali Reza Solaimany Nazar, and Mohsen Motevasel. "CFD simulation of nanofluid heat transfer considering the aggregation of nanoparticles in population balance model." Journal of Thermal Analysis and Calorimetry (2020): 1-14.

https://doi.org/10.1007/s10973-019-09218-0

[34] Phu, Nguyen Minh, and Nguyen Van Hap. "Performance Evaluation of a Solar Air Heater Roughened with Conic-Curve Profile Ribs Based on Efficiencies and Entropy Generation." Arabian Journal for Science and Engineering 45 (2020): 9023-9035. https://doi.org/10.1007/s13369-020-04676-3

[35] Van Nguyen, Hap, Trinh Thi Minh Nguyen, Phu Minh Nguyen, and Tu Thien Ngo. "Computational fluid dynamics analysis for basement ventilation in case of a fire." Journal of Advanced Marine Engineering and Technology 44, no. 4 (2020): 333-337. https://doi.org/10.5916/jamet.2020.44.4.333

[36] Yilmaz, M. "The effect of inlet flow baffles on heat transfer." International communications in Heat and Mass Transfer 30, no. 8 (2003): 1169-1178. https://doi.org/10.1016/s0735-1933(03)00182-9

[37] Phu, Nguyen Minh, and Geun Sik Lee. "Characteristics of pressure and force considering friction in a closed cylinder with a holed piston." Journal of Mechanical Science and Technology 28, no. 6 (2014): 2409-2415. https://doi.org/10.1007/s12206-014-0533-4 